\title{
DESENVOLVIMENTO SUSTENTÁVEL E CONCEPÇÕES DE PROFESSORES DE BIOLOGIA EM FORMAÇÃO INICIAL
}

\author{
Magnólia Fernandes Florêncio de Araújo* \\ Maria Arminda Pedrosa**
}

RESUMO: No contexto do que propõe a Década de Educação para Desenvolvimento Sustentável, a decorrer até 2014, foram avaliadas concepções de professores de Biologia em formação sobre desenvolvimento sustentável e práticas para o promover. Os inquiridos revelaram concepções que remetem para uma visão protecionista e conservacionista de desenvolvimento sustentável. A maioria deles referiu práticas ligadas a desenvolvimento sustentável, como reciclagem ou economia de água e energia, relacionando-as com políticas públicas, tanto globais, como locais. Porém, as práticas educativas estão entre as menos citadas como relacionadas com desenvolvimento sustentável. Assim, discute-se a necessidade de se desenvolverem ações educativas com enfoque em sustentabilidade ambiental, aliada a desenvolvimento social e econômico, enquanto pilares em que assenta desenvolvimento sustentável e, consequentemente, em sua promoção na prática pedagógica.

Palavras-chave: Desenvolvimento sustentável. Educação em ciências. Professores em formação.

\section{SUSTAINABLE DEVELOPMENT IN THE PERCEPTION OF BIOLOGY INITIAL TEACHER EDUCATION}

ABSTRACT: In the context of the Decade of Education for Sustainable Development, going from 2005 to 2014, conceptions of Biology teachers about sustainable development and practices that promote this goal were identified. Most responses showed a protectionist and conservationist view of sustainable development. Most respondents reported practices concerning sustainable development, such as recycling or saving water and energy, and connected these practices with public policies, both global and local. Neverthless, educational practices were among the least quoted as concerning sustainable development. The needs for developing educational activities focusing on environmental sustainability, in articulation with social and economic development, is discussed as a means to reorient science education towards sustainable development, and hence, promoting it in the pedagogical practice.

Keywords: Sustainable development. Environmental sustainability. Science education. Initial teacher education. 


\section{INTRODUÇÃO}

Todas as atividades humanas se relacionam, em diferentes graus, com ambientes naturais. Essas relações entre os sistemas humano e natural são tão dinamicamente interdependentes e interconectadas que tornam esses sistemas coadaptados, com reações recíprocas (DALE; NEWMAN, 2005) e, por essa razão, conhecimentos práticos sobre problemas ambientais não devem limitar-se aos de cientistas ambientais, biólogos ou ecólogos. O modo como todas as pessoas são afetadas pelas questões ambientais requer uma educação para todos, com um conhecimento prático dos princípios fundamentais e de uma série de conceitos e suas inter-relações, envolvidos na tomada de decisões individuais e sociais naquilo que diz respeito ao ambiente e se relaciona com economia e sociedade.

Enquanto conceito dinâmico, a Educação para Desenvolvimento Sustentável engloba uma nova perspectiva de educação, a qual procura integrar todas as pessoas e levá-las a assumir responsabilidades por criarem um futuro sustentável (FREIRE, 2007). Ensinar e aprender ciências para a sustentabilidade torna-se, pois, fundamental.

O conceito de sustentabilidade é absolutamente novo e implica aceitar que a Terra não é tão grande e sem limites como nós acreditamos e não pode suportar indefinidamente os efeitos de muitas atividades antrópicas predadoras (VILCHES et al., 2012). É hoje consensual que as discussões sobre desenvolvimento sustentável precisam incluir as vertentes de desenvolvimento humano e social, superando as visões tradicionais orientadas pela perspectiva conservacionista e protecionista (MARTINEZ, 2012), resultando em recomendações de que, em contextos educativos, trabalhar sustentabilidade inclua a identificação de concepções dos destinatários sobre esse tema.

Nesse sentido, o objetivo do presente trabalho foi avaliar as concepções de professores de Biologia em formação sobre desenvolvimento sustentável, procurando responder às seguintes questões:

Que ideias de desenvolvimento sustentável se identificam em alunos de Biologia, professores em formação? Que dimensões esses licenciandos consideram estar incluídas em desenvolvimento sustentável? Que implicações poderiam ter essas concepções na sua prática docente?

\section{Referencial teórico}

A situação de emergência planetária em que vivemos é marcada por uma série de graves problemas que se encontram estreitamente relacionados entre si, destacando-se: a contaminação e a degradação, sem fronteiras, de recursos naturais; o esgotamento e a destruição desses recursos, implicando perda da biodiversidade e desertificação; a urbanização acelerada e desordenada; a degradação generalizada dos ecossistemas; os desequilíbrios insustentáveis representados pelo hiperconsumo de uma pequena parte da humanidade contra fome e condições insuportáveis em que vive a maioria da população mundial (VILCHES ; GIL-PEREZ, 2011). Essa 
série de problemas se traduz em conflitos de diversos tipos, perda de diversidade cultural, situações de guerra e terrorismo, de modo que embora pareça que existe consciência sobre a maioria desses problemas, não se observam ações globais eficazes para amenizar essas situações.

Formas inovadoras de cuidar dos sistemas sociais e ecológicos foram discutidas por laureados com o Nobel, políticos e decisores governamentais, culturais e econômicos ${ }^{1}$. Discutiram-se soluções concretas para desenvolvimento sustentável global baseadas em três temas principais:

- Reconexão com a biosfera, tratando do papel do capital natural e do ambiente para o desenvolvimento da sociedade e para promover o bem-estar humano.

- O planeta, que dominado pela humanidade faz emergir o antropoceno época geológica correspondente a esse domínio -, bem como tentativas de identificação de espaço operacional seguro para a humanidade continuar a desenvolver-se num planeta estável.

- Propostas de transformações em larga escala no sentido da sustentabilidade mundial. O documento final apresenta mensagens-chave para salvaguardar o desenvolvimento a longo prazo e, consequentemente, evitar o colapso do planeta. Destacam ligações da humanidade com os ecossistemas, mudanças ambientais impressas no planeta - antropoceno -, e inovações socioecológicas que podem levar a uma reconexão positiva com o ambiente (MOBERG ; SIMONSEN, 2011).

Especificamente na educação em ciências, pesquisas desenvolvidas em diversos países com professores de ciências referem que a atual crise planetária é uma dimensão esquecida (VILCHES et al., 2004). Assim, face à situação de emergência planetária (GIL-PEREZ ; VILCHES, 2006), a educação para um futuro sustentável deveria ser uma prioridade, tal como se preconiza em iniciativas como a Década de Educação para Desenvolvimento Sustentável ${ }^{2}$, constituindo-se um imperativo em todas as áreas educativas. Inserir educação para desenvolvimento sustentável (EDS) em cursos de formação de professores de ciências é essencial e urgente, uma vez essa associação, além de envolver compromissos político-educativos a diversos níveis (e.g. estados, países e regiões geopolíticas), requer um ensino integrador. Este deve apelar à responsabilização individual e comunitária relativamente à consecução de desenvolvimento sustentável, no presente e no futuro, ou seja, um desenvolvimento que não contempla apenas as necessidades e aspirações das gerações atuais, mas que também inclua margens necessárias para as gerações vindouras. Numa avaliação feita à metade da Década de Educação para Desenvolvimento Sustentável, considera-se que as sementes da pesquisa em EDS têm sido implantadas, mas que o suporte para tais pesquisas, especialmente no ensino superior, parece ainda bastante limitado (UNESCO, 2009).

A década de EDS “dá ênfase ao papel central da educação na busca comum pelo desenvolvimento sustentável” (UNESCO, 2005, p.9) e tem por objetivo "integrar os valores inerentes ao desenvolvimento sustentável em todos os aspectos da aprendizagem com o intuito de fomentar mudanças de comportamento que permitam criar uma sociedade sustentável e mais justa 
para todos" (UNESCO, 2005, p.16). Constitui-se, assim, em um chamado aos educadores de todas as áreas e níveis, pela via da educação formal e não formal, para contribuir para a formação de cidadãos e cidadãs conscientes da gravidade dos problemas ambientais enfrentados hoje pela humanidade e preparados para participar em tomadas de decisões adequadas (VILCHES et al., 2007).

Por outro lado, as interações entre a humanidade e o ambiente, assim como o desenvolvimento de políticas, tecnologias e estratégias para se alcançar um futuro mais sustentável, estão entre os aspectos mais complexos com que atualmente se tem que lidar. Compreender problemas complexos inerentes a tais interações e eventuais soluções ou estratégias de mitigação envolvem, necessariamente, aspectos interdisciplinares, os quais são difíceis de integrar, especialmente porque os conhecimentos estão organizados em disciplinas tradicionais e em áreas do conhecimento altamente especializadas, dificultando pesquisas necessárias para desenvolvimento sustentável e educação para o promover. O fato de se continuar tentando resolver problemas ambientais específicos e pontuais pode ser reflexo dessa educação compartimentada que dificulta ou impede que se desenvolvam abordagens gerais, coerentes e consistentes com a promoção de um futuro sustentável.

Diante disso, O que podemos fazer? é a questão apresentada por Vilches e Gil-Perez (2011), remetendo para a necessidade de os educadores refletirem sobre ações concretas, em todos os níveis de ensino, para se construir um futuro sustentável. Nesse contexto, como iniciativas apropriadas, sugere-se divulgar a problemática da sustentabilidade e integrá-la em educação formal e não formal visando contribuir para criar espaços e ações sustentáveis nas diversas comunidades, incluindo a escolar, além de desenvolver uma formação cidadã, participar em pesquisas sobre sustentabilidade e apoiar a década de EDS 3 .

\section{METODOLOGIA DA INVESTIGAC̣ÃO}

A pesquisa se desenvolveu numa abordagem qualitativa e quantitativa, decorrente dos objetivos definidos. Nesta seção, apresentam-se aspectos metodológicos fundamentais, designadamente a caracterização da amostra, do instrumento de coleta de dados e da análise dos dados recolhidos.

\section{A amostra}

Nesta investigação, participaram 121 estudantes do curso de licenciatura em Ciências Biológicas de uma universidade pública do nordeste do Brasil, os quais foram convidados a assinar um termo de consentimento livre e esclarecido e autorizaram as pesquisadoras a utilizar as suas respostas em publicações. Todos os alunos eram concluintes ou estavam finalizando o terceiro ano do curso, já tendo, portanto, cumprido a maior parte da carga horária de formação. 


\section{0 instrumento de coleta de dados}

Um questionário compreendendo diversos aspectos relacionados com desenvolvimento sustentável foi o instrumento utilizado na investigação. Neste trabalho, entretanto, tratar-se-á apenas daquilo que se refere a concepções de desenvolvimento sustentável e dimensões relacionadas com esse tipo de desenvolvimento, analisando respostas dos inquiridos a três questões (duas abertas e uma fechada) contidas no instrumento, e apresentadas a seguir.

- Os termos sustentabilidade e desenvolvimento sustentável difundiram-se rapidamente e são utilizados, hoje, praticamente de forma unânime e global. Para você, o que significa desenvolvimento sustentável?

- O termo desenvolvimento sustentável comporta a(s) dimensão(ões):

(a) Social (b) Econômica (c) Ecológica (d) Cultural (e) Política (f) Ambiental

- Exemplifique pelo menos duas ações que você acredita estarem relacionadas a desenvolvimento sustentável.

É importante ressaltar que as questões formuladas foram, inicialmente, submetidas à revisão de três especialistas da área e de dez alunos de pós-graduação em Desenvolvimento e Meio Ambiente e em Ensino de Ciências, tendo sofrido algumas modificações resultantes das sugestões recolhidas.

\section{A análise dos dados}

As respostas às questões discursivas foram analisadas com base na Técnica de Elaboração e Análise de Unidades de Significado, proposta por Moreira, Simões e Porto (2005). As etapas envolvem a análise de relato ingênuo, que corresponde à leitura do que o respondente escreve na sua forma exata, sem modificações, seguida da identificação de atitudes em que se procura ter uma visão do todo, separandose as unidades mais significativas para a criação de indicadores e categorias que emergem das respostas e que referenciam a interpretação e, por fim, a interpretação, que se dá após estar montado o quadro geral das ideias de cada sujeito, bem como as convergências e divergências identificadas. Nesta etapa, faz-se uma análise interpretativa do fenômeno, buscando compreendê-lo na sua essência, a partir de literatura relevante sobre o tema.

Do ponto de vista quantitativo, a análise envolveu a contagem dos números de respostas por categoria emergente e os cálculos das respectivas frequências e percentagens. Algumas vezes, identificou-se mais de uma ideia chave do mesmo sujeito, motivo pelo qual as somas das frequências de respostas correspondentes às diferentes categorias são superiores a 100\%. 


\section{RESULTADOS E DISCUSSÃO}

Esta seção organiza-se em três subseções diretamente relacionadas com os grupos de respostas às três questões apresentadas, que correspondem a: concepções de desenvolvimento sustentável, dimensões de desenvolvimento sustentável e ações associadas a desenvolvimento sustentável.

\section{Concepções de desenvolvimento sustentável}

Quando questionados diretamente sobre o significado de desenvolvimento sustentável, mais da metade dos alunos fez referência a um desenvolvimento sem agressão à natureza ou à utilização do ambiente para o sustento da bumanidade sem exaurir seus recursos (tabela 1$)$.

Tabela 1: Pontos de vista de estudantes de Biologia, professores em formação, sobre desenvolvimento sustentável.

\begin{tabular}{|c|c|c|}
\hline Categorias: expressões mais utilizadas & $\mathbf{N}=\mathbf{1 2 1}$ & $\%$ \\
\hline Desenvolvimento sem agressão à natureza & 38 & 31 \\
\hline Utilização do ambiente para o sustento da humanidade sem esgotá-lo & 36 & 30 \\
\hline Utilização dos recursos ambientais de forma correta ou com pouco impacto & 31 & 25 \\
\hline Desenvolvimento com proteção do ambiente para gerações futuras & 29 & 24 \\
\hline Ações de proteção/respeito/preservação da natureza & 24 & 20 \\
\hline Desenvolvimento sem utilização da natureza & 11 & 9 \\
\hline Desenvolvimento com equilíbrio/harmonia & 9 & 7 \\
\hline Reaproveitamento/reciclagem de recursos naturais & 6 & 5 \\
\hline
\end{tabular}

De um modo geral, as respostas mais utilizadas na definição de desenvolvimento sustentável (as três primeiras linhas da tabela, que somam 86\%) expressam noções superficiais, imprecisas e frágeis, que remetem para uma concepção claramente protecionista, preservacionista e conservacionista, com uma conotação quase puramente ambiental. Embora proteger, preservar e conservar o ambiente seja, de fato, uma necessidade para um futuro sustentável, a simples citação desses aspectos, em resposta à questão formulada, revela uma visão ingênua, vaga e imprecisa, em que estão ausentes as dimensões sociais e econômicas. Os graves desequilíbrios existentes entre grupos humanos, envolvendo conflitos étnicos e culturais, por exemplo, não foram citados em nenhuma ocasião. Além disso, a ideia de que é possível um desenvolvimento sem a utilização da natureza deixa claro que muitos separam as dimensões econômicas e sociais dos sistemas naturais.

As impressões sobre desenvolvimento sustentável reveladas confirmam o predomínio de certas crenças incorretas, como: sermos uma espécie dominante e independente da natureza; os recursos naturais serem gratuitos e inesgotáveis; a 
tecnologia estar ao nosso alcance para resolver a maioria dos nossos problemas; a natureza ter capacidade infinita para assimilar os resíduos que produzimos; adquirir e acumular bens ser determinante para se ter sucesso - item fundamental (CORTESE, 1999). Constatou-se, aqui, uma clara relação entre crescimento e desenvolvimento, demonstrando que urge mudar concepções e perspectivas sobre relações entre ambiente, pessoas e desenvolvimento (econômico e social) no âmbito da formação docente, como forma de superarmos os problemas identificados.

A formação dos estudantes aqui referidos passa por disciplinas denominadas "Ciências da Natureza e Realidade", "Física e Meio Ambiente", "A Vida no Ambiente", "Alterações Ambientais", "Conservação da Vida" e "Educação Ambiental", além de contar, na orientação do seu projeto pedagógico, com o tema gerador "Seca e Água". A perspectiva era, portanto, de que a formação desses professores pudesse apontar para a discussão da sustentabilidade ambiental e de suas dimensões, em termos regionais. Acredita-se, pois, que poderia haver uma maior integração entre a temática do curso, que é oferecido em região semiárida, e as discussões atuais sobre desenvolvimento sustentável, o que lhes permitiria ampliar a visão sobre essa questão, fator fundamental na prática docente futura dos licenciandos.

Esporadicamente, termos como Obediência às leis (1), Ética (1), Medidas educativas (2), Autossuficiência (3), Qualidade de vida (3), Consciência ambiental (4), Uma visão mais "planetária" da questão (5) e Responsabilidade (6) foram citados, mas sem o estabelecimento de inter-relações com as dimensões ambiental, ecológica e cultural, consideradas nas definições encontradas na literatura para o conceito de desenvolvimento sustentável (UNESCO, 2005; CALIXTO ; PRADOS, 2008). Observa-se, assim, que a ideia de desenvolvimento sustentável envolvendo um modelo de desenvolvimento econômico global que alia as dimensões social, ambiental e econômica, a fim de garantir o acesso aos recursos naturais das gerações atuais, bem como das gerações futuras, é pouco evidente, ou revela-se de maneira inconsistente e vaga nas respostas dos participantes. Esses aspectos e suas repercussões na formação docente dos licenciandos estão sendo avaliados em outras pesquisas.

\section{Dimensões de desenvolvimento sustentável}

Solicitados a apontarem dimensões integradas em desenvolvimento sustentável, apenas 39\% dos inquiridos concordaram que todos os termos tinham relação com esse conceito (figura 1). As dimensões ecológica e ambiental foram quase unânimes, como era previsível, mas cerca de 30\% não considerou que as dimensões cultural e política estejam ligadas a desenvolvimento sustentável. Embora esse percentual não seja elevado, ele indica que esses aspectos de desenvolvimento sustentável ainda são negligenciados por uma percentagem expressiva de futuros professores de ciências. 
Figura 1: Dimensões de desenvolvimento sustentável.

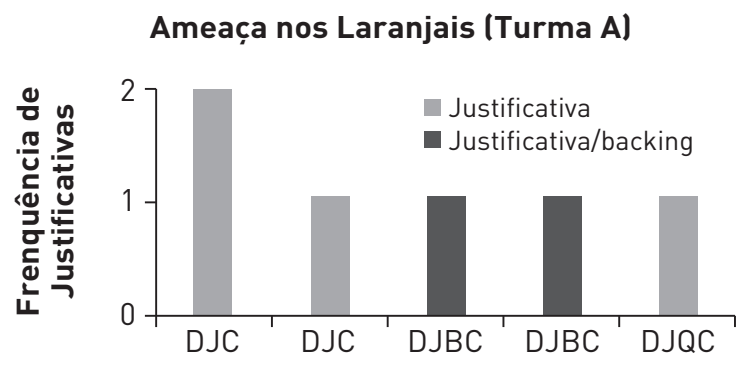

Combinações do TAP (a)

\section{Ações relacionadas a desenvolvimento sustentável}

Ao indicarem ações relacionadas a desenvolvimento sustentável (Quadro 1), a grande maioria dos inquiridos referiu práticas ligadas a desenvolvimento sustentável, como reciclagem ou economia de água e energia, relacionando-as com políticas públicas, tanto globais como locais. Os resultados aqui encontrados revelam que práticas educativas estiveram entre as menos citadas e que os participantes consideram as ações de gestores públicos ou privados mais ligadas a desenvolvimento sustentável do que suas próprias práticas pessoais.

Quadro 1: Categorização das ações relacionadas a desenvolvimento sustentável, mencionadas pelos inquiridos

(121) percentagem de respostas por categoria, ações e número de inquiridos que referiu cada ação.

\begin{tabular}{|c|c|}
\hline Categorias & Ações e número de inquiridos por ação \\
\hline $\begin{array}{c}\text { Práticas educativas } \\
\text { e comportamentos } \\
\text { pessoais (27\%) }\end{array}$ & $\begin{array}{r}\text { Economia de água e energia (18), uso de veículos não poluentes (2), } \\
\text { consumo consciente (6). }\end{array}$ \\
\hline $\begin{array}{c}\text { Políticas públicas locais } \\
\text { ou globais (65\%) }\end{array}$ & $\begin{array}{c}\text { Coleta seletiva do lixo (9), reciclagem (35), agricultura sustentável, } \\
\text { reflorestamento (12), aumento de recursos econômicos para as } \\
\text { famílias de baixa renda, exploração racional dos recursos naturais } \\
\text { (5), preservação cultural (5), empresas e indústrias ecologicamente } \\
\text { corretas (5), uso de fontes renováveis de energias/biocombustíveis (8). }\end{array}$ \\
\hline $\begin{array}{c}\text { Práticas educativas } \\
\text { protetivas (11\%) }\end{array}$ & $\begin{array}{c}\text { proteção do ambiente, conscientização ambiental (7), educação } \\
\text { ambiental(7), preservação da biodiversidade, preservação } \\
\text { ambiental (6). }\end{array}$ \\
\hline
\end{tabular}

Observa-se, pois, que a maioria dos inquiridos considerou que desenvolvimento sustentável deve se dar a partir de ações que se desenrolam no âmbito de políticas públicas locais ou globais. Não se percebeu um estabelecimento claro de relações entre políticas públicas dos órgãos de poder, participação dos cidadãos e envolvimento do sistema escolar na construção de um mundo que se desenvolva de modo mais sustentável. 
Entre as ações chave de educação para a sustentabilidade, destacam-se consumo responsável (reciclar, reduzir, reutilizar) e comércio justo, com a produção e compra de produtos obtidos a partir de procedimentos que respeitam o ambiente e as pessoas (VILCHES et al., 2009). Exercer a cidadania, inclusive pela via política, com efetiva participação da sociedade civil, é apresentado como um ponto de destaque, além dos pequenos esforços pessoais que, somados, resultam em grandes avanços para a redução do gasto de energia e da contaminação ambiental, sendo fatores considerados imprescindíveis em educação para a sustentabilidade. Tais aspectos poderiam ser enfatizados na formação desses docentes, especialmente por se tratar de um curso da área ambiental.

A formação inicial de professores de ciências, como algo que se dá nas instituições de ensino superior, envolvendo ações de ensino, aprendizagem e pesquisa, deve ter aí um ponto de apoio significativo para proporcionar a construção de conhecimentos sobre desenvolvimento sustentável e estimular reflexão e discussão sobre formas de se enfrentar o desafio de o promover. São necessárias, pois, ações educativas que transformem concepções, hábitos e perspectivas, designadmente em termos de participação social e desenvolvimento de políticas ambientais indispensáveis para se avançar no sentido de haver sociedades sustentáveis. É necessário que essas ações se apresentem bem fundamentadas, o que requer estudos científicos que permitam compreender corretamente a situação e pensar em medidas de atuação adequadas (VILCHES et al., 2009). Também estão necessariamente implicadas aqui ações mais amplas, conjuntas, de caráter planetário, tendo em vista os denominados problemas sem fronteiras (GIL- PEREZ; VILCHES, 2009).

Nesse contexto, a redução da pobreza é um item fundamental para o alcance de um mundo mais sustentável. Para o Programa das Nações Unidas para o Desenvolvimento (PNUD):

A perspectiva centrada na pobreza permite-nos examinar as privações ambientais no acesso - a combustível moderno para cozinhar, água potável e saneamento básico. Estas privações absolutas, já de si importantes, constituem graves violações dos direitos humanos. O fim destas privações poderia aumentar capacidades de ordem superior, alargando as escolhas das pessoas e fazendo progredir o desenvolvimento humano (PNUD, 2011, p.5).

A "redução da pobreza" não foi apontada pelos participantes da pesquisa como ação relacionada com desenvolvimento sustentável, embora "qualidade de vida" tenha sido citada por três deles, o que poderá indicar alguma preocupação também com "redução da pobreza". De fato, numa perspectiva comunitária e global, ou seja, que não se centre numa visão individual e egocêntrica, não é viável promover "qualidade de vida" à revelia da "redução da pobreza". 


\section{CONCLUSÕES E PERSPECTIVAS}

A necessidade de uma educação para desenvolvimento sustentável com o atual enfoque que envolve sustentabilidade ambiental aliada a desenvolvimento socioeconômico é evidente. As concepções dos participantes estão majoritariamente associadas a visões conservacionistas e protecionistas, que apontam para uma compreensão de que essas ações são eficazes para o desenvolvimento sustentável, ou para a superação de problemas ambientais, os quais, na realidade, estão interconectados com outros (de natureza social ou econômica, por exemplo) e que exigiriam uma visão mais holística da sua gênese e dos fatores que devem ser ponderados para os solucionar ou mitigar.

Consideráveis citações sobre equilíbrio, respeito ou harmonia com a naturez̧a podem estar relacionadas com a ideia de que os recursos naturais são ilimitados, e que é possível continuar a utilizá-los largamente porque são suficientemente abundantes para atender às necessidades humanas, não obstante o tempo limite para isso, ou a restrição que as gerações futuras sofrerão, ainda mais que as atuais.

O curso de Ciências Biológicas do qual os participantes desta pesquisa são alunos aponta, no seu projeto pedagógico, o tema gerador "Seca e Água", uma problemática local, como norteador da proposta das disciplinas de formação. Embora não tenha sido objeto deste trabalho avaliar o projeto pedagógico do referido curso, observou-se que, de maneira geral, não há o cumprimento dessa prerrogativa na maioria das disciplinas curriculares, mas em apenas algumas delas. Essa indicação poderia favorecer as discussões da temática do desenvolvimento sustentável regional numa perspectiva atual e em todas as suas dimensões, incuindo aspectos sociais e econômicos, fato que não se revela na visão da maioria dos estudantes. Estudos adicionais estão sendo realizados na perspectiva de conhecer como se desenvolvem as disciplinas do curso para uma melhor compreensão dessa questão.

\section{A educação em ciências para um mundo sustentável: sugestões para a formação docente}

As declarações e deliberações internacionais para a orientação de programas educativos, em especial as chamadas boas práticas em EDS, e o modo como a formação de professores pode contribuir para a sustentabilidade são ressaltados por Pedrosa (2010):

A educação em ciências, tal como a educação em geral, deve orientar-se para o desenvolvimento de competências, incluindo as necessárias para compreender problemas de sustentabilidade que atualmente se colocam, tanto a nível local como global, um requisito essencial para se poder ponderar percursos de resolução e/ou contribuir com atuações efetivas para os resolver ou mitigar. Embora tal orientação requeira contributos diversos, a sua concretização não é possível à revelia dos professores e a sua efetivação depende fortemente do seu empenho e envolvimento, os quais, por seu turno, requerem a conjugação de diversos fatores, incluindo oportunidades de formação que estimulem o acesso à informação e recursos relevantes (PEDROSA, 2010, p.356). 
Nessa perspectiva, considerando-se que a sustentabilidade tem aspectos de natureza local, com implicações globais, e que há questões globais que afetam a todos e a cada um, a educação científica tem um papel fundamental e deve avançar especialmente no que se refere à formação de professores de ciências, de modo a que futuros docentes:

a) Desenvolvam princípios básicos de sustentabilidade, como a redução do consumo e da produção de resíduos, reciclagem e reutilização de materiais.

b) Compreendam que as questões ambientais estão ligadas a processos sociais e econômicos, promovendo leituras coerentes com a complexidade da realidade ambiental.

c) Reconheçam as múltiplas inter-relações das questões ambientais, econômicas e sociais, locais e globais, numa visão sistêmica do ambiente.

d) Desenvolvam competências para analisar os conflitos socioambientais, debater propostas de resolução e tomar decisões individuais e coletivas.

Neste sentido, para um futuro sustentável, merecem atenção especial os seguintes temas ${ }^{4}$ : Sustentabilidade; Educação para sustentabilidade; Crescimento econômico e sustentabilidade; Crescimento demográfico; Tecnologias para a sustentabilidade; Redução da pobreza; Igualdade de gêneros; Luta contra a contaminação sem fronteiras; Consumo responsável; Turismo sustentável; Direitos humanos; Diversidade cultural; Mudanças climáticas; Biodiversidade; Urbanização e sustentabilidade; Nova cultura de água e energia; Esgotamento de Recursos; Governo universal; Luta contra a desertificação; Redução de desastres, conflitos e violências. Tais temas devem ser trabalhados nos cursos de formação de professores, permitindo uma aplicação prática às realidades de cada um e das comunidades, sem perder de vista o contexto mundial, numa perspetiva de formação de cidadãos bem informados e organizados, capazes de tomar decisões adequadas para contribuir para a resolução de situações complexas com as quais têm que lidar cada vez mais.

\section{NOTAS}

\footnotetext{
${ }^{1}$ http://globalsymposium2011.org/

${ }^{2}$ http://www.oei.es/decada.

${ }^{3}$ http://www.oei.es/decada/educadores.pdf

${ }^{4}$ http://www.oei.es/decada/indice.php
} 


\section{REFERÊNCIAS BIBLIOGRÁFICAS}

CALIXTO, P. S.; PRADOS, M.A.H. La evolución del concepto de sostenibilidad y su incidencia en la educación ambiental. Teoría de La Educación, Salamanca, v.20, p. 179-204, 2008. Disponível em: $<$ http://campus.usal.es/ revistas_trabajo/index.php/1130-3743/article/viewFile/989/1087>. Acesso em: 08 mai. 2012.

CORTESE, A. D. Education for Sustainability: the Need for a New Human Perspective. Boston: Second Nature, 1999. Disponível em: < http://amper.ped.muni.cz/ miler/aktivity/Ecology/ possum/humanpersp.pdf $>$. Acesso em 24 de fevereiro de 2012.

DALE, A.; NEWMAN, L. Ustainable development, education and literacy. International Journal of Sustainability and Higher Education, Hamburgo, v. 6, n. 4, p. 351-362, 2005.

FREIRE, M. A. Educação para a Sustentabilidade: Implicações para o Currículo Escolar e para a Formação de Professores. Pesquisa em Educação Ambiental, São Paulo, v. 2, n. 1, p. 141-154. 2007.

GIL PÉREZ, D.; VILCHES, A. Contribución de la ciencia a la cultura ciudadana. Culturay Educación, Barcelona, v. 6, n. 3, p. 259-272, 2004.

GIL-PEREZ, D.; VILCHES, A. Algunos obstáculos e incomprensiones en torno a la sostenibilidad. Revista Eureka sobre Enseñanza y Divulgación de las Ciências, Cádiz, v. 3, n. 3, p. 507-516, 2006.

GIL PÉREZ, D.; VILCHES, A. La educación ambiental en la década de la educación para la sostenibilidad. In: LÓPEZ HERRERÍAS, J. A. (Ed.). El agua y la educación ambiental en la década del desarrollo sostenible. Madrid: Asociación Española de Educación Ambiental, 2009. p. 13-31.

MARTINEZ, J. J. B.; 2012. Retos para la sostenibilidad en el Área metropolitana Del Valle de Aburrá de Antioquia Colômbia: percepciones acerca de lo que entendemos por este término y ejemplos de actividades educativas. Revista Eureka sobre Enseñanza y Divulgación de las Ciências, Cádiz, v. 9, n. 2, p. 278-293, 2012.

MOBERG, F.; SIMONSEN, S. H. (Eds). Executive Summary of scientific background reports, Nobel Laureate Symposium on Global Sustainability. Estocolmo: Stockholm University, 2011. 20p.

MOREIRA, W. W.; SIMÕES, R.; PORTO, E. Content analysis: elaboration technique and signified units analysis. Revista Brasileira de Ciência e Movimento, Brasília, v. 13, n. 4, p. 107-114, 2005.

PEDROSA, M. A. Ciências, educação científica e formação de professores para desenvolvimento sustentável. Revista Eureka sobre Enseñanza y Divulgación de las Ciências, Cádiz, v. 7, p. 346-362, 2010.

Programa das Nações Unidas para o Desenvolvimento (PNUD). Relatório do Desenvolvimento Humano 2011. Sustentabilidade e Equidade: um futuro melhor para todos. Washington: PNUD, 2011. 183p.

UNESCO. Década da Educação das Nações Unidas para um Desenvolvimento Sustentável, 2005-2014: documento final do esquema internacional de implementação. Brasília: UNESCO, 2005. 120p.

UNESCO. Review of Contexts and Structures for Education for Sustainable Development. Paris: UNESCO, 2009. 80p.

VILCHES, A.; GIL-PÉREZ, D.; EDWARDS, M. A actual crise planetária: uma dimensão esquecida na educação em ciência. Revista de Educação, Porto, v. XII, n. 2, p. 59-73, 2004.

VILCHES, A. et al. Respuesta educativa a la situación de emergencia planetaria: necesidad de planteamientos y acciones globales. Investigación en la Escuela, Sevilla, v. 63, p. 5-16, 2007. Disponível em: < http://www.uv.es/gil/documentos_enlazados/2007_Inv_en_la_Esc.pdf >. Acesso em 08 de maio de 2013.

VILCHES, A.; MACÍAS, O.;GIL-PÉREZ, D. Década de la educación para la sostenibilidad. temas de acción clave. In: Organização de Estados Ibero-Americanos (OEI). Doc. Trab. N. 1. Madri, Espanha: Centro de Altos Estudios Universitarios de la OEI, 2009.

VILCHES, Amparo et al. The need for contributions to the decade of education for a sustainable future: an ethical commitment. In: GONÇALVES, F., PEREIRA, R., FILHO, W.L., AZETEIRO, U.M. (eds.). Contributions to the decade of education for sustainable development. Frankfurt: Peter Lang GMBH, 2012. p. 11-32. 
VILCHES, Amparo; GIL PÉREZ, Daniel. El Antropoceno como oportunidad para reorientar el comportamiento humano y construir un futuro sostenible. Revista Electrónica de Enseñanza de las Ciências, Vigo, v. 10, n. 3, p. 394-419, 2011. Disponível em: http://reec.uvigo.es/volumenes/ volumen10/REEC_10_3_1.pdf. Acesso em 08 de maio de 2013.

Data Recebimento: 09/05/2013

Data Aprovação: 30/04/2014

Data Versão Final: 28/05/2014

\section{Contato:}

Universidade Federal do Rio Grande do Norte, Centro de Biociências, Departamento de Microbiologia e Parasitologia. Av. Senador Salgado Filho, 3000 - Lagoa Nova - - Natal, RN - Brasil CEP: 59072970 
